\title{
Metabolic syndrome susceptibility of suckling male and female rats given oral administration of natural honey compared with cane syrup
}

\author{
Abdulwahid Ajibola \\ Department of Human Physiology, Faculty of Medicine, Kaduna State University, P.M.B 2339, Kaduna 800001, Kaduna State, Nigeria.
}

\begin{tabular}{l}
\hline ARTICLE INFO \\
\hline Article history: \\
Received on: $17 / 02 / 2017$ \\
Accepted on: $22 / 06 / 2017$ \\
Available online: 17/01/2018 \\
\hline Key words: \\
Honey, Metabolic substrates, \\
Cane syrup, metabolic \\
syndrome, rats.
\end{tabular}

\begin{abstract}
The acute effects of natural honey (NH) and cane syrup (golden syrup, GS) on metabolism in 89 (10-day old) suckling Sprague Dawley rats were investigated. Low dose group fed $10 \mathrm{ml} / \mathrm{sg}$ of either NH or GS; high dose group gavaged with $20 \mathrm{mls} / \mathrm{kg}$ of either solution; while the fifth group, control received $10 \mathrm{mls} / \mathrm{kg}$ distilled water. All treatments were administered via stomach tube twice daily for 10 consecutive days. The pups were euthanized on day 21 for the measurements of metabolic substrates and long bones. All the dietary treatments induced significant $(p<0.001$, ANOVA) body weight gain. There was no difference $(p \geq 0.05)$ amongst all the groups in all the parameters measured (NFG; NFT; hepatic lipids and glycogen; as well as length and weight of the femur and the tibia), except the values of plasma free fatty acids $(\mathrm{p}<0.0001)$ and hepatic lipid content $(\mathrm{p}<0.001)$ that were significantly higher in GS-fed than the honey fed pups. The study showed that despite the rapid growth phase of the neonatal pups shown as BW gain, the adverse effects associated with the consumption of refined sugars, did not manifest prominently within the short term, but could develop with chronic exposure as previously reported.
\end{abstract}

\section{INTRODUCTION}

Several studies have implicated the consumption of sucrose and fructose including high fructose corn syrup (HFCS) in the epidemiology and pathogenesis of metabolic syndrome, MetS [1-6], a group of risk factors that predispose people to diabetes, renal and metabolic diseases [1]. Children are also not spared from the scourge of MetS due to their high intake of sugars as reported by [5] [6]. The intake of refined sugars had risen in recent times [4] [5], especially fructose due to the cheaper cost of production of HFCS relative to sucrose as reported by [4]. The manufacturers of beverages and other carbonated-water products now sweetened their products with the cheaply produced HFCS as observed elsewhere [4] in a bid to safe cost. However, this reduction in production cost was not devoid of another price as it has been noted by some researchers

\footnotetext{
* Corresponding Author Abdulwahid Ajibola, Department of Human Physiology, Faculty of Medicine, Kaduna State University, P.M.B 2339, Kaduna 800001, Kaduna State, Nigeria.Email: ajibola66 @ gmail.com
}

[3] [4] [6] that high intake of refined sugars is taking a toll on the health of human populace. The incidence and prevalence of this health hazard associated with high intake of refined sugars, Mets has also been reported from studies on children [5] [6], and according to some findings, $30 \%$ overweight children are susceptible [6]. The search for a substitute for refined sugars becomes imperative in order to curb this menace of MetS. Honey appears to be a source of natural sugars as substitute for the artificial sugars, and it was reported by [7] to be protective against hypertriglyceridemic and prooxidative effects of fructose. Although, major consumption of natural honey $(\mathrm{NH})$ is by adults, but as reported by most researchers, some traditional rites include the feeding of honey to infants at birth [8] [9]. However, there is a dearth of scientific information on the effect of feeding honey to neonates. The few data available was oral administration for a very short period [9] [10]. The inclusion of refined sugars in infant formula has also been documented [11]. The need to evaluate the safe limits of honey consumption vis-a-vis refined sugars in children becomes imperative. Suckling Sprague Dawley (SD) rats were fed as animal models for 10 days with natural honey and cane syrup, a form of sucrose presented as golden syrup, GS to compare their metabolic effects. 


\section{MATERIALS AND METHODS}

The study was approved by the Animal Ethics Screening Committee (AESC approval number - 2010/29/2B) of the University of the Witwatersrand, South Africa, and performed according to the humane handling rules contained in the "Guidelines for the use and care of animals in Experimental, Education and other Scientific Procedures" of the University of the Witwatersrand, South Africa. The experimental procedures were done in the Animal unit of Central Animal Services (CAS) and the School of Physiology at the University of the Witwatersrand, South Africa.

\subsection{Animals}

Eight nursing Sprague-Dawley (SD) rats with their litters of 89 pups (body weight $23.4 \pm 0.33 \mathrm{~g}$ [range $18-26 \mathrm{~g}$ ]), provided by the CAS, University of the Witwatersrand, Johannesburg, South Africa was used for the study. The pups with their respective dams were housed as a family in well ventilated, solidbottom plastic cages ( $425 \times 270 \times 140 \mathrm{~mm}$ ) with beddings of clean, hard wood shavings mixed with shredded papers for environmental enrichment. The environmental temperature was set at $22 \pm 2^{\circ} \mathrm{C}$ and the lighting on a $12 \mathrm{~h} \mathrm{~L}$ : D cycle, lights on at 07:00hours and switched off at 19:00hours. The dams were supplied with standard rat cubes (Epol, Johannesburg, South Africa) and tap water ad libitum.

\subsection{Experimental procedure}

The 89 (7-day old) suckling pups comprised of 46 males and 43 females. The birth date of the pups was noted as day one, and on day seven, they were randomly assigned to the five dietary treatment groups. Each dam had pups belonging to all the groups for fair representation. They were allowed to adapt to the housing conditions and experimental interventions (handling, weighing and gavaging) for three days before the beginning of the experimental protocol. The familiarization to experimental procedures included oral treatment with $0.1 \mathrm{ml}$ of $50 \%$ solution of their requisite dietary supplements (NH or golden syrup, GS) for the first three days (d 7-9). The oral gavaging was done using a plastic orogastric gavaging needle and $1 \mathrm{ml}$ hypodermic syringe. The pups in the control group were also gavaged with $0.1 \mathrm{ml}$ distilled water in a similar manner, such that they were also exposed to same handling like the treatment groups. The dietary treatments with either $\mathrm{NH}$ or GS were replicated on the basis of sex (male and female) in each group.

\subsection{Experimental design}

The experimental procedure lasted 10days (age $10-$ 20d). At the age of $10 \mathrm{~d}$ old, the pups in each litter were gavaged orally with either distilled water diluted GS or $\mathrm{NH}(50 \%$ concentration) or distilled water for control according to their groups. The feeding was done by oral gavaging using a plastic orogastric gavaging needle and $1 \mathrm{ml}$ hypodermic syringe. The $\mathrm{NH}$ or GS dietary supplements were given in either of two doses (low or high), twice daily at 12 hours interval, every morning $(07 \mathrm{~h} 00$ $08 \mathrm{~h} 00)$ and evening $(19 \mathrm{~h} 00-20 \mathrm{~h} 00)$ for 10 days. The rats in the low dose-diet groups were given $10 \mathrm{ml} / \mathrm{kg}$ of $50 \%$ solution, twice a day; whilst the high dose-diet groups were given $20 \mathrm{ml} / \mathrm{kg}$ of $50 \%$ solution twice daily. The pups in the control group were gavaged likewise with $10 \mathrm{ml} / \mathrm{kg}$ distilled water every morning and evening, using a plastic orogastric gavaging needle and $1 \mathrm{ml}$ hypodermic syringe. The pups were allowed to suckle ad libitum between gavage. The groups were Group 1, Control (CON); Group 2,Golden syrup Low (GSL); Group 3, Natural honey Low (NHL); Group 4, Golden syrup High (GSH); and Group 5, Natural honey High $(\mathrm{NHH})$. There were nine rats per group except $\mathrm{CON}$ males, and GSH and NHH female groups that had eight rats each whilst $\mathrm{n}=10$ in GSH and NHH male groups.

\subsection{Proximate analysis}

The proximate analysis (on dry matter basis) of the chemical composition of the undiluted honey and golden syrup (used as the pups' dietary supplements) as determined by the South African National Accreditation Systems (SANAS) accredited Analytical laboratory (Irene Analytical Services, Agricultural Research Council (ARC), Irene, South Africa) according to the method [12].

\subsection{Monitoring of linear growth}

The growth of the experimental animals was monitored daily throughout the study by measuring their body weight using Ohaus Scout ${ }^{\mathrm{TM}}$ Pro digital balance (Ohaus Corporation, New York, USA). The cane syrup used was supplied in form of the commercially available golden syrup, GS (golden syrup ${ }^{\circledR}$, Illovo Sugar Ltd, Natal, South Africa). The dilution of the golden syrup and honey was done so as to avoid gavaging the young rats with thick substances that could clog their respiratory tracts.

The rats were further dissected to remove the right long bones (femur and tibia) for measurement as indicators of linear growth. The bones were carefully defleshed, and the right femoral head was removed gently from the acetabulum at the hip joint. The muscles and soft tissues were removed from the femur and tibia, and the length of the bones was measured using thread and a metric ruler. In measuring the length of the femur, the femoral neck was used as a reference point to avoid the effect of the anatomy of the femoral head on the measurements. The bones were then dried in a Salvis vacucenter oven (Oakton®, USA) at $40^{\circ} \mathrm{C}$ for 7 days (until constant weight was obtained), and then weighed using a Precisa $310 \mathrm{M}$ digital balance (Precisa ${ }^{\circledR}$, Vadodara, Switzerland) to determine their dry weight. The density was then estimated by the formula [13]:Bone density $(\mathrm{mg} / \mathrm{mm})=$ dry bone weight $(\mathrm{mg}) / \mathrm{bone}$ length $(\mathrm{mm})$.

\subsection{Blood collection}

On day 21 (after the last dietary treatment), the nonfasting glucose (NFG) was determined in the rats using a glucometer, which was calibrated with a Code strip (provided by the manufacturers) prior to the NFG measurement. The rat's tail 
was disinfected with an alcohol swab (Patient Care ${ }^{\circ}$, Johannesburg, South Africa). Then, one drop of blood was collected from the tail vein of each rat via pin prick with a sterile $22 \mathrm{G}$ needle after disinfecting the tail according to [14]. The blood was used to measure NFG with the glucometer (Glucometer Elite ${ }^{\circ}$, Kyoto, Japan) on glucose test strip (Ascensia Elite ${ }$, Bayer (PTY) Ltd, Isando, South Africa). Subsequently, the rats were euthanized with intra-peritoneal injection of sodium pentobarbitone $\left(150 \mathrm{mg} / \mathrm{kg}\right.$ ) (Euthanaze ${ }^{\circledR}$, Centaur Laboratories, Johannesburg, South Africa). The thorax of each animal was cut open and $2 \mathrm{mls}$ of blood was collected by cardiac puncture using $2 \mathrm{ml}$ syringes and $21 \mathrm{G}$ needles. The blood sample poured into heparin coated tube (Greiner Bio-one GnebH, Austria) was gently inverted so that the blood mixed with heparin to prevent the blood from clotting. The blood samples were subsequently centrifuged with a Sorvall $®$ RT $6000 \mathrm{~B}$ (Du Pont, USA) at $4^{\circ} \mathrm{C}$ and 5000 x G for 15 minutes to obtain plasma. The plasma samples collected were frozen at $-20^{\circ} \mathrm{C}$ for later clinical biochemistry. The TG meter was calibrated using a Code strip provided by the manufacturers prior to the determination of the non-fasting triglycerides (NFT). During the blood sampling, one drop of blood collected via cardiac puncture was used to determine triglyceride concentrations, with a TG meter, (Accutrend® Cobas, Roche, Mannhein, Germany) on TG test strips (Roche Diagnostics, Germany).

\subsection{Liver collection}

The rats were then meticulously dissected to collect the liver which was weighed on a digital balance (Precisa®, Vadodara, Switzerland), before the liver storage at $-20^{\circ} \mathrm{C}$ for later analyses of lipid and glycogen contents. The liver glycogen was determined indirectly by acid hydrolysis of the liver glycogen to glucose and then measurement of glucose [15]. The liver lipids were extracted by standard procedures using chloroform: methanol $(2: 1)$ and quantified according to [16].

\subsection{Data analyses}

The results were expressed as mean \pm SEM. GraphPad Prism for Windows Version 5.02 (GraphPad Software, San Diego, California, USA) was used for data analyses. The Student's t-test was used for the analysis of NH and GS shown in Table 1. The other parameters were analysed by one-way analysis of variance (ANOVA) with Neuman-Keul's post hoc used as a multiple comparison test. The level of significance was set at a $p$ value of less than $0.05(\mathrm{p}<0.05)$, except otherwise stated.

\section{RESULTS AND DISCUSSION}

\subsection{Proximate analysis}

The proximate analysis (on dry matter basis) of the chemical composition of the undiluted honey and golden syrup is presented in Table 1.

This investigation constitutes the first study on the acute effects of natural honey compared with cane syrup administered orally (over a 10-day period) in form of golden syrup on metabolic activities in 10-day old suckling male and female Sprague-Dawley (SD) rats. There are anecdotal evidences encouraging the feeding of honey to new born babies by some customs and traditions with little or no scientific data as back-up to the practice [8] [9]. In 2009, [17] concluded from their New Zealand behavioural study in animals that early introduction of honey diet is beneficial and can improve memory loss and cognitive decline associated with ageing. Another study on the palatability of honey feeding in infants reports that honey is well tolerated and significantly reduces the crying phases of babies than sterile water [9]. In the study on the importance of honey relative to sucrose in children's nutrition, honey-fed infants were found to have improved haematological profiles and calcium uptake, no digestion problem, lighter and thinner faeces, better skin colour, less susceptibility to diseases, and steady weight gain [9]. These positive effects of honey in infant nutrition are attributed to its effects on the digestion process, and one possible cause is the effect of honey constituent, oligosaccharides on intestinal flora of these children [11].

Table 1: Chemical composition (dry matter basis) of the undiluted forms of natural honey $(\mathrm{NH})$ and golden syrup (GS) used for orogastric gavaging of the experimental rats.

\begin{tabular}{ccc}
\hline Proximate analyses & Natural honey $(\mathbf{N H})$ & Golden syrup $(\mathbf{G S})$ \\
\hline Dry matter $(\%)$ & $84.08 \pm 0.07$ & $83.38 \pm 0.01$ \\
Energy $(\mathrm{MJ} / \mathrm{Kg})$ & $15.56 \pm 0.21$ & $15.55 \pm 0.06$ \\
Glucose $(\mathrm{g} / 100 \mathrm{~g})$ & $43.35 \pm 0.02$ & $42.37 \pm 0.03$ \\
Fructose $(\mathrm{g} / 100 \mathrm{~g})$ & $37.64 \pm 0.01$ & $36.46 \pm 0.02$ \\
Sucrose $(\mathrm{g} / 100 \mathrm{~g})$ & $2.03 \pm 0.05$ & $26.03 \pm 0.00^{\beta}$ \\
Maltose $(\mathrm{g} / 100 \mathrm{~g})$ & $2.75 \pm 0.02$ & not detected \\
Glycemic sugars $(\%)$ & $76.71 \pm 1.55$ & $77.03 \pm 0.91$ \\
Protein* $(\%)$ & $0.42 \pm 0.06$ & $0.25 \pm 0.05$ \\
Fat $(\%)$ & $0.53 \pm 0.01$ & $0.62 \pm 0.00$ \\
Other nutrients $(\%)$ & $0.53 \pm 0.00$ & $0.17 \pm 0.00$ \\
\hline
\end{tabular}

*Obtained by multiplying nitrogen content by the factor of $6.25 ;{ }^{\beta}$ significantly higher $(\mathrm{p}<0.0001)$ than the sucrose in natural honey.

\subsection{Dietary treatment}

The NH and GS solutions fed to the neonatal animals were iso-caloric in their undiluted forms, and each has less than $0.5 \%$ protein content, and as such the pups were exposed to substrates with similar nutritional values. However, NH contains minerals, vitamins and other micronutrients according to [18], thus higher value of the other nutrients found in NH than GS (Table 1). Nonetheless, no dietary supplement compromises the nutrient requirements of suckling rats. As such the dietary treatments did not confer any obvious nutritional advantage of one diet over the other. This reflected in the body weight gain of all the experimental animals over the 10-day dietary treatment period.

\subsection{Growth}

The results of the linear growth of our experimental rats evaluated through the measurements of weight and length of the long bones (femur and tibia) are shown in Table 2. The values obtained showed that the bones are not significantly different in length amongst the groups. There were also marginal insignificant differences in the bones' weight and the bone density calculated as $\mathrm{mg} / \mathrm{mm}$ in the animals (Table 2). 
The body weight gain (BWG) was obtained from the difference in the initial weight and terminal weight, and were used to assess the growth pattern of the experimental rats on gender basis (male and female). The terminal body weight showed that the treatment diets induced significant BWG $(\mathrm{p}<0.001)$ in all the rats relative to initial weight (Figures 1 and 2).

Table 2: Weight, length, and bone density $(\mathrm{mg} / \mathrm{mm})$ of the femur and tibia in male and female suckling rats at 20 days of age after 10 days of dietary intervention.

\begin{tabular}{|c|c|c|c|c|c|c|c|}
\hline Diet & Sex & $\begin{array}{c}\text { Femur Weight } \\
(\mathrm{mg})\end{array}$ & $\begin{array}{c}\text { Length } \\
(\mathrm{mm})\end{array}$ & $\begin{array}{c}\text { Density } \\
(\mathrm{mg} / \mathrm{mm})\end{array}$ & $\begin{array}{c}\text { Tibia Weight } \\
\text { (mg) }\end{array}$ & $\begin{array}{c}\text { Length } \\
(\mathbf{m m})\end{array}$ & $\begin{array}{c}\text { Density } \\
(\mathrm{mg} / \mathrm{mm})\end{array}$ \\
\hline \multirow[t]{2}{*}{$\mathrm{CON}$} & $\mathrm{M}$ & $65.3 \pm 2.32$ & $15.0 \pm 0.26$ & $4.35 \pm 0.12$ & $51.3 \pm 1.67$ & $17.7 \pm 0.21$ & $2.91 \pm 0.10$ \\
\hline & $\mathrm{F}$ & $67.3 \pm 1.74$ & $14.9 \pm 0.26$ & $4.54 \pm 0.14$ & $51.6 \pm 2.17$ & $17.6 \pm 0.20$ & $2.94 \pm 0.14$ \\
\hline \multirow[t]{2}{*}{ GSL } & $\mathrm{M}$ & $66.4 \pm 3.56$ & $15.0 \pm 0.24$ & $4.42 \pm 0.20$ & $49.4 \pm 3.74$ & $17.7 \pm 0.31$ & $2.78 \pm 0.19$ \\
\hline & $\mathrm{F}$ & $62.1 \pm 4.03$ & $14.3 \pm 0.29$ & $4.34 \pm 0.26$ & $50.6 \pm 3.38$ & $17.3 \pm 0.18$ & $2.92 \pm 0.17$ \\
\hline \multirow[t]{2}{*}{ NHL } & $\mathrm{M}$ & $68.9 \pm 1.46$ & $15.1 \pm 0.28$ & $4.55 \pm 0.08$ & $53.1 \pm 1.36$ & $17.6 \pm 0.22$ & $3.03 \pm 009$ \\
\hline & $\mathrm{F}$ & $63.7 \pm 2.02$ & $14.9 \pm 0.46$ & $4.30 \pm 0.14$ & $50.7 \pm 2.13$ & $17.6 \pm 0.20$ & $2.88 \pm 0.11$ \\
\hline \multirow[t]{2}{*}{ GSH } & $\mathrm{M}$ & $62.8 \pm 3.49$ & $14.6 \pm 0.20$ & $4.29 \pm 0.24$ & $47.8 \pm 2.58$ & $17.0 \pm 0.28$ & $2.81 \pm 0.12$ \\
\hline & $\mathrm{F}$ & $59.5 \pm 3.24$ & $14.5 \pm 0.34$ & $4.10 \pm 0.17$ & $46.3 \pm 2.38$ & $17.2 \pm 0.31$ & $2.70 \pm 0.12$ \\
\hline \multirow[t]{2}{*}{ NHH } & $\mathrm{M}$ & $64.8 \pm 2.56$ & $14.9 \pm 0.28$ & $4.33 \pm 0.10$ & $49.9 \pm 3.44$ & $17.1 \pm 0.28$ & $2.91 \pm 0.17$ \\
\hline & $\mathrm{F}$ & $65.2 \pm 3.30$ & $14.8 \pm 0.40$ & $4.38 \pm 0.12$ & $49.5 \pm 2.29$ & $17.5 \pm 0.34$ & $2.82 \pm 0.09$ \\
\hline
\end{tabular}

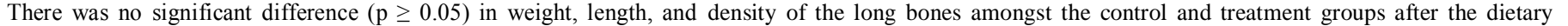
treatment.

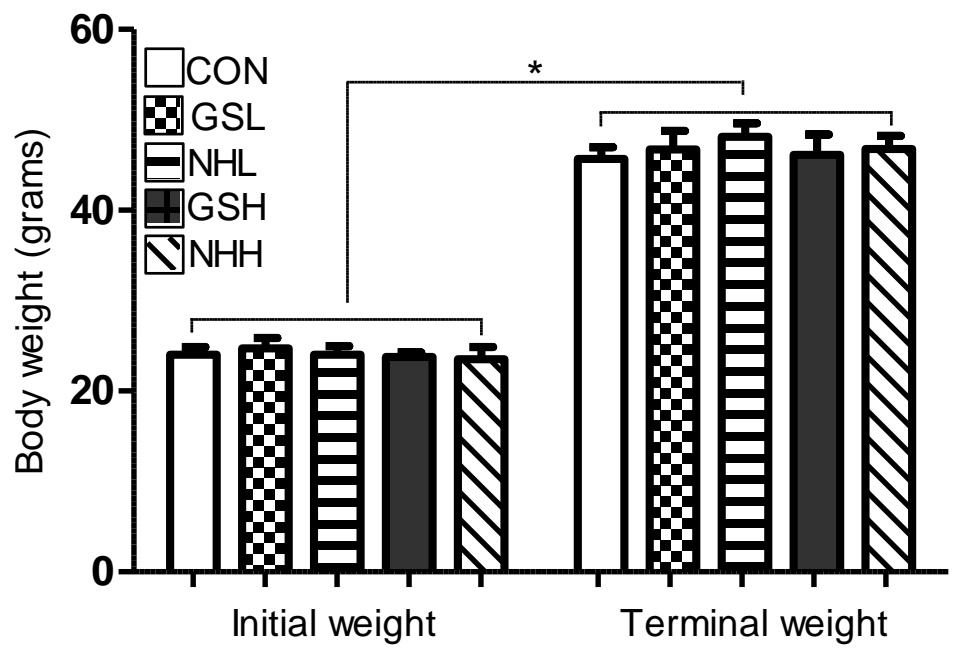

Fig. 1: Effects of treatment diets on body weight gain of suckling male rats at 20 days of age. CON, control (n=8); GSL, golden syrup low dose (n=9); NHL, natural honey low dose $(n=9)$; GSH, golden syrup high dose $(n=10)$; NHH, natural honey high dose $(n=10)$. *Significant increase $(P<0.001)$ in body weight gain for all groups after 10-day treatment vs initial weight.

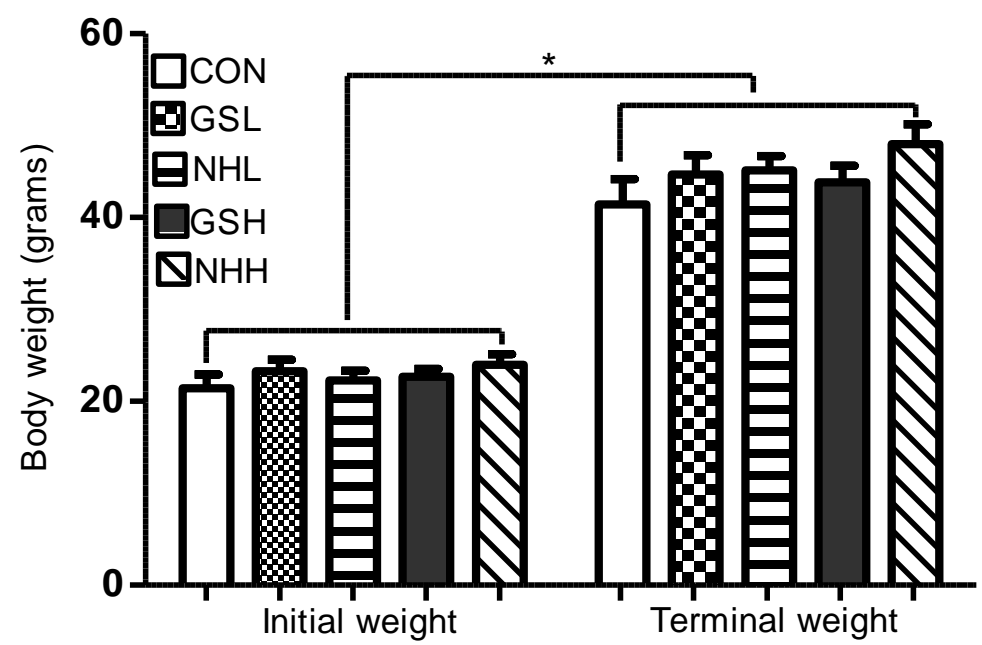

Fig. 2: Effects of treatment diets on body mass gain of suckling female rats at 20 days of age. CON, control ( $n=9)$; GSL, golden syrup low dose (n=9); NHL, natural honey low dose $(n=9)$; GSH, golden syrup high dose $(n=8)$; NHH, natural honey high dose $(n=8)$. *Significant increase $(\mathrm{P}<0.001)$ in body weight gain for all groups after 10-day treatment vs initial weight. 
The study showed that orogastric administration of natural and refined sugars over a period of 10 days had a growth promoting effect in suckling rats. In one nutritional study recently conducted in our laboratory [10], the rate of growth and development of rat pups can be greatly altered by varying supplements administered to them during the suckling period. This is also corroborated by the findings on the neonates of other mammals [19] [20] [21]. Contrary to these records, the BWG of our honey-fed rats did not differ significantly from the BWG obtained from the CON and GS-nurtured rats (Figures 1 and 2). However, BWG alone is not a reliable measure of growth because according to one report [22] this may be influenced by various factors like food intake, obesity and hydration status.

The tibial length has been used by many workers as a more accurate indicator of linear growth instead of the BWG [22] [23].The results obtained from measuring the tibial weight in males showed marginal increase with the honey-fed thus NHL vs GSL: $7.49 \%$ weight, $8.99 \%$ density; NHL vs CON: $3.51 \%$ weight, $4.12 \%$ density; NHH vs GSH: $4.39 \%$ weight, $3.56 \%$ density. The measurements of the femur obtained from male rats also presented a similar increase pattern thus - NHL vs GSL: $3.77 \%$ weight, $2.9 \%$ density; NHL vs CON: $5.51 \%$ weight, $4.6 \%$ density; $\mathrm{NHH}$ vs GSH $3.18 \%$ weight, $0.93 \%$ density. There were no differences in weight and density of both bones between male NHH and CON rats, as well as amongst all the female groups. The marginal linear growth shown as enhanced weight and density of the tibia and femur of honey-fed rats might be due to absorption of the calcium content of the honey supplement. According to one study, calcium constituent of a diet has influence on bone growth [24]. This is also buttressed by a previous nutritional study that bone mineralisation could manifest as the increased bone density observed in these experimental rats [25]. This gives credence to the growth influence of natural honey shown in adult rats as reported elsewhere [26].

\subsection{Metabolic substrates}

The differences in non-fasting blood glucose and triglycerides, as well as cholesterol levels measured were not significant amongst the treatment and control groups (Table 3). However, the marginal increase of both NFG and NFT in the GS-fed rats over the honey-fed and CON groups could manifest as early signs of MetS. This was an indication of the tendency to develop full blown MetS with chronic exposure to cane syrup feeding, as shown from our previous studies in adult animal models [25] [26]. The significantly higher $(\mathrm{p}<0.0001)$ concentration of FFA in the GS-fed rats in the present study (Table 3 ) is also a trait of MetS. This MetS trait forms part of the findings of diet induced metabolic dysfunctions reported in experimental rats fed from 7 days old to 13 weeks of age [25]. These metabolic abnormalities include hypercholesterolemia, hyperinsulinemia and increased hepatic fat stores, as well as inclination to hyperglycaemia in the cane syrup-fed male rats, unlike the normoglycaemic honey-fed rats reported from the adult study.

The liver dry weight and the hepatic store of metabolic substrates (lipids and glycogen) were recorded in Table 4. Cane syrup dietary supplements induced significantly higher $(\mathrm{p}<0.001)$ hepatic lipid content than honey, whilst there was no difference ( $\mathrm{p}$ $\geq 0.05$ ) amongst all the experimental animals in the amount of glycogen in hepatic storage as shown in Table 4.

The excessive consumption of sugar yields high amounts of its constituent monosaccharides, glucose and fructose. Dietary fructose is known to have a direct impact on hepatic lipid metabolism by bypassing the enzyme phosphofructokinase, the regulatory step imposed on glucose [27]. The elevated FFA and hyperlipidaemia of our GS-fed rats in the present study could have resulted from the unregulated flow of fructose-derived carbons into lipogenesis. These MetS traits were not associated with the honey-fed rats probably due to the influence of the various phytochemical constituents of honey on its glucose and/or fructose metabolism and/or absorption [18].

The results suggested that the experimental animals in this study were exposed to sub-adverse levels of refined sugar, as several previous studies [1-6] have associated high sugar intake with hyperglycaemia and hypertriglyceridemia. Male rats are not known to be resistant to abdominal obesity, hyperglycaemia, dyslipidaemia and other risk factors of renal and metabolic diseases. As documented by some researchers [7], adult female rodents are less susceptible to the adverse effects of sucrose consumption [28]. However, there was no gender differences in our neonatal rats fed with cane syrup. This plausibly confirmed that the resistance to MetS by the female rats reported by these workers [28] is associated with age and the hormonal factor responsible manifest at adult age of the rodent's life [29].

Table 3: Circulating metabolic substrates in male and female suckling rats at 20 days of age after 10 days of dietary intervention

\begin{tabular}{|c|c|c|c|c|c|}
\hline Diet & Sex & NFG (mg/dL) & NFT (mmol/L) & FFA (mmol/L) & Cholesterol (mmol/L) \\
\hline \multirow[t]{2}{*}{ CON } & $\mathrm{M}$ & $5.37 \pm 0.11$ & $1.90 \pm 0.26$ & $0.17 \pm 0.01$ & $4.26 \pm 0.39$ \\
\hline & $\mathrm{F}$ & $5.26 \pm 0.58$ & $1.66 \pm 0.20$ & $0.15 \pm 0.01$ & $4.24 \pm 0.41$ \\
\hline \multirow[t]{2}{*}{ GSL } & $\mathrm{M}$ & $5.91 \pm 0.12$ & $1.80 \pm 0.25$ & $0.25 \pm 0.01 *$ & $3.95 \pm 0.35$ \\
\hline & $\mathrm{F}$ & $5.81 \pm 0.10$ & $2.00 \pm 0.26$ & $0.23 \pm 0.01 *$ & $4.29 \pm 0.15$ \\
\hline \multirow[t]{2}{*}{ NHL } & $\mathrm{M}$ & $5.73 \pm 0.16$ & $1.49 \pm 0.12$ & $0.16 \pm 0.02$ & $3.74 \pm 0.25$ \\
\hline & $\mathrm{F}$ & $5.27 \pm 0.41$ & $1.66 \pm 0.27$ & $0.16 \pm 0.01$ & $3.66 \pm 0.26$ \\
\hline \multirow[t]{2}{*}{ GSH } & $\mathrm{M}$ & $6.28 \pm 0.17$ & $1.52 \pm 0.26$ & $0.22 \pm 0.01 *$ & $3.89 \pm 0.18$ \\
\hline & $\mathrm{F}$ & $6.02 \pm 0.21$ & $1.68 \pm 0.25$ & $0.23 \pm 0.01 *$ & $3.80 \pm 0.30$ \\
\hline \multirow[t]{2}{*}{ NHH } & $\mathrm{M}$ & $5.59 \pm 0.18$ & $1.45 \pm 0.21$ & $0.17 \pm 0.01$ & $3.96 \pm 0.20$ \\
\hline & $\mathrm{F}$ & $5.07 \pm 0.40$ & $1.26 \pm 0.09$ & $0.16 \pm 0.01$ & $3.74 \pm 0.34$ \\
\hline
\end{tabular}


Table 4: Liver dry weight, and hepatic lipid and glycogen content (as glucose equivalents) in male and female suckling rats at 20 days of age after 10 days of dietary intervention.

\begin{tabular}{lcccc}
\hline Diet & Sex & Liver weight $(\mathrm{g})$ & Liver lipid (\% Liver weight) & Liver glycogen (as glucose equivalents) (mmol/L) \\
\hline CON & M & $0.27 \pm 0.01$ & $4.41 \pm 0.46$ & $2.97 \pm 0.40$ \\
& F & $0.27 \pm 0.02$ & $5.65 \pm 0.33$ & $2.76 \pm 0.39$ \\
GSL & M & $0.30 \pm 0.02$ & $6.96 \pm 0.61 *$ & $3.04 \pm 0.47$ \\
& F & $0.24 \pm 0.02$ & $7.87 \pm 0.16^{*}$ & $2.03 \pm 0.43$ \\
NHL & M & $0.28 \pm 0.02$ & $4.79 \pm 0.30$ & $2.91 \pm 0.48$ \\
& F & $0.27 \pm 0.02$ & $5.70 \pm 0.47$ & $2.79 \pm 0.67$ \\
GSH & M & $0.30 \pm 0.02$ & $6.98 \pm 0.30^{*}$ & $3.01 \pm 0.46$ \\
& F & $0.26 \pm 0.02$ & $7.40 \pm 0.61 *$ & $2.21 \pm 0.63$ \\
NHH & M & $0.28 \pm 0.02$ & $4.32 \pm 0.13$ & $2.58 \pm 0.35$ \\
& F & $0.30 \pm 0.02$ & $5.34 \pm 0.13$ & $2.79 \pm 0.36$ \\
\hline
\end{tabular}

*value significantly different across the column $(\mathrm{p}<0.0001)$.

In general, the oral administration of both artificial (GS) and natural $(\mathrm{NH})$ sugars are well tolerated by neonatal animals. However, the marginal insignificant differences amongst the groups may suggest that metabolic changes are influenced by the cumulative effects of chronic intake of refined sugars, as well as level of exposure and age effects. Hence, it becomes imperative to exercise caution when feeding artificial sweeteners to neonates, as high sugar intake has been shown responsible for various metabolic health problems seen in the young ones in their growing phase [5] [6]. As reported by some authors, natural honey is a better dietary substitute to refined sugars because $\mathrm{NH}$ is highly nutritive; palatable; mitigates gastrointestinal problems; and provides antioxidative as well as other protective effects [7-11] [18]. One will be doing well to children by giving them natural honey to replace sweets and other sugary substances they are often inclined to eat.

This assertion has been justified by extensive reviews on the nutraceutical values of natural honey [30] [31]. These authors adduced the multi-systemic protective effects of natural honey to its synergistic multiple ingredients factor (SMIF).

\section{CONCLUSION}

The findings showed that both artificial (GS) and natural (NH) sugars are safe for consumption by neonatal animals, and by extension human infants and children. However, it is advisable that children should eat refined sugars cautiously to avert the metabolic health hazards associated with excessive fructose intake. Natural honey as a sweetener is a better alternative and a beneficial nutritional substitute to refined sugars. Nonetheless, there is need for further studies to investigate the possible mechanisms of sugar metabolism indicative of metabolic syndrome tendency, as well as the mechanistic insights into SMIF, said to be responsible for the protective effects of this functional food, honey.

\section{CONFLICT OF INTEREST}

The author declares that there is no conflict of interest related to the publication of this manuscript. Part of this work was accepted for presentation as an abstract titled "Metabolic response of suckling male and female rats to oral administration with honey compared to cane syrup" at the $32^{\text {nd }}$ Annual Conference and Scientific meeting, Physiological Society of Nigeria (PSN) held at the Department of Physiology, College of Medical Sciences, University of Calabar, Nigeria on $22^{\text {nd }}-24^{\text {th }}$ August, 2012.

\section{ACKNOWLEDGEMENT}

This study was funded by the Tertiary Education Trust Fund (TETFund), Abuja, Nigeria as part of PhD programme. The work was also supported by grants from the National Research Foundation (NRF) of South Africa; the University of the Witwatersrand; and the Faculty of Veterinary Science, University of Pretoria. The Central Animal Services, University of the Witwatersrand, South Africa provided the experimental animals. The author also thanked Ms. Janine Donaldson, Mr.Busisani Lembede and Mr. Owen Karimanzira for their technical assistance.

\section{REFERENCES}

1 Rutledge AC, Adeli K. Fructose and the metabolic syndrome: pathophysiology and molecular mechanisms. Nutrition Review. 2007;65: S13-S23.

2 Tappy L, Le K. Metabolic effects of fructose and the worldwide increase in obesity. Physiological Review. 2010; 90: 23 - 69.

3 Ouyang X, Cirillo P, Sautin Y, McCall S, Bruchette JL, Diehl AM, Johnson RJ, Abdelmalek MF. Fructose consumption as a risk factor for non-alcoholic fatty liver disease. Journal of Hepatology. 2008; 48 (6): $993-999$.

4 Bernardes N, Ayyappan P, De Angelis K, Bagchi A, Akolkar G, Dias DS, Bello-Klein A, Singal PK. Excessive consumption of fructose causes cardiometabolic dysfunctions through oxidative stress and inflammation. Canadian Journal of Physiology and Pharmacology. eFirst Article 2017 February 10 doi: 10.1139/cjpp-2016-0663.

5 Cruz ML, Goran MI. The metabolic syndrome in children and adolescents. Current Diabetes Reports. 2004; 4: 53 - 62.

6 Stanhope KL, Schwarz JM, Keim NL, Griffen SC, Bremer AA, et al. Consuming fructose-sweetened, not glucose-sweetened, beverages increases visceral adiposity and lipids and decreases insulin sensitivity in overweight/obese humans/ Journal of Clinical Investigation. 2009; 119:1322-1334. doi:10.1172/JCI37385.

7 Busserolles J, Gueux E, Rock E, Mazur A, Rayssiquier Y. Substituting honey for refined carbohydrates protects rats from hypertriglyceridemic and prooxidative effects of fructose. Journal of Nutrition, 2002. 132: $3379-3382$.

8 Al-Bukhari M. (2008). The Translation of the Meanings of Sahih AlBukhari, Arabic- English. Translated by Dr Muhammad Muhsin 
Khan. Published by Dar Us Salam Publishers and Distributors, Riyadh 11416, Kingdom of Saudi Arabia. Vol. 7, Bk. 71, nos. 584, $585,588,603$.

9 Ramenghi LA, Amerio G, Sabatino G. Honey, a palatable substance for infants: from De Rerum Natura to evidence-based medicine. European Journal of Pediatrics. 2001; 160: 677 - 678.

10 Ajibola A, Olusakin J, Oyewale AA. Growth and metabolic response of suckling rats fed with natural honey supplements, International Journal of Food and Nutritional Science. 2016; 3(1): 1 - 5.

11 Rivero-Urgell M, Santamaria-Orleans A. Oligosaccharides: application in infant food (review). Early Human Development. 2001; 65: $43-52$.

12 AOAC. Official methods of analysis ( $18^{\text {th }}$ Edition). Association of Analytical Chemists, Washington DC, USA. 2011

13 Monteagudo MD, Hernandez ER, Seco C, Gonzalez-Riola J, Revilla M, Villa LF, Rico H. Comparison of the bone robusticity index and bone weigth/bone length index with the results of bone densitometry and bone histomorphometry in experimental studies.Acta Anatomical. 1997; 160: 195 - 199.

14 Loxham SJG, Teague J, Poucher SM, De Schoolmeester J, Turnbull $\mathrm{AV}$, Carey F. Glucagon challenge in the rat: a robust method for the in vivo assessment of Glycogen phosphorlyase inhibitor efficacy, Journal of Pharmacological and Toxicological Methods. 2007; 55: 71 $-77$.

15 Passoneau JV, Lauderdale VR. A comparison of three methods of glycogen measurement in tissues. Analytical Biochemistry. 1974; 60: $405-412$.

16 Bligh EG, Dyer WJ. A rapid method of total lipid extraction and purification. Canadian Journal of Biochemistry and Physiology. 1959; 37: $911-917$.

17 Chepulis LM, Starkey NJ, Waas JR, Molan PC. The effects of longterm honey, sucrose or sugar-free diets on memory and anxiety in rats. Physiology \& Behavior. 2009; 97: 359 - 368

18 Ajibola A. Physico-chemical and physiological values of honey and its importance as a functional food. International Journal of Food and Nutritional Science. 2015; 2 (6): 1 - 9.

19 Baumgarner BL, Nagle AM, Quinn MR, Farmer AE, Kinsey ST. Dietary supplementation of $\beta$-guanidinopropionic acid ( $\beta \mathrm{GPA}$ ) reduces whole-body and skeletal muscle growth in young CD-1 mice. Molecular \& Cellular Biochemistry. 2015; 403(1-2): 277 - 285.

20 Yang HS, Xiong X, Wen QQ, Yin YL. Effects of dietary supplementation with ethanolamine on intestine development and growth performance of weaned piglets.Journal of Animal Science. 2016;94(3):79-81.

21 Lin G, Wang X, Wu G, Feng C, Li D, Wang J, Zhou H. Improving amino acid nutrition to prevent intrauterine growth restriction in mammals. Amino Acids. 46(7) 2014 March doi: 10.1007/s00726$014-1725-\mathrm{z}$
22 Elahi MM, Matata BM. Effects of maternal high-fat diet and statin treatment on bone marrow endothelial progenitor cells and cardiovascular risk factors in female mice offspring fed a similar diet. Nutrition. 2017; 35: 6 - 13 .

23 Fritton JC, Myers ER, Wright TM, van der Meulen MCH. Loading induces site specific increases in mineral content assessed by microcomputed tomography of the mouse tibia. Bone. 2005;36: $1030-$ 1038.

24 Tylavsky FA. Nutrition influences bone growth in children, Journal of Nutrition. 2004; 134: 689S - 690S.

25 Ajibola A, Chamunorwa JP, Erlwanger KH. Dietary supplementation with natural honey promotes growth and health of male and female rats compared to cane syrup, Scientific Research \& Essays. 2013; 8: $543-553$.

26 Ajibola A, Chamunorwa JP, Erlwanger KH. Comparative effects of dietary supplementation with natural honey and cane syrup on the morphometry of viscera in growing male and female rats. Indian Journal of Experimental Biology.2013; 51: 303 - 312.

27 Khitan Z, Kim DH. Fructose: A key factor in the development of metabolic syndrome and hypertension, Journal of Nutrition and Metabolism 2013; doi.org/10.1155/2013/682673.

28 Busserolles J, Mazur A, Gueux E, Rock E, Rayssiquier Y.Metabolic syndrome in the rat: females are protected against the pro-oxidant effect of a high sucrose diet.Experimental Biology and Medicine. 2002; 227: 837 - 842 .

29 Galipeau DM, Yao L, McNeil JH. Relationship among hyperinsulinemia, insulin resistance, and hypertension is dependent on sex, American Journal of Physiology - Heart and Circulatory Physiology. 2002; 283: H562 - H567.

30 Ajibola A, Chamunorwa JP, Erlwanger KH. Nutraceutical values of natural honey and its contribution to human health and wealth, Nutrition \& Metabolism (Lond).2012; 9: 61.

31 Ajibola A. Novel insights into the health importance of natural honey. Malaysian Journal of Medical Science.2015; 22: 7 - 22.

\section{How to cite this article:}

Ajibola A. Metabolic syndrome susceptibility of suckling male and female rats given oral administration of natural honey compared with cane syrup. J App Biol Biotech. 2018; 6 (1): 1319. 